\title{
Apolipoprotein E4 Allele in Subjects with COVID-19
}

\author{
Jaroslav Alois Hubacek ${ }^{a, b} \quad$ Lucie Dlouha $^{a, c} \quad$ Ladislav Dusek $^{\text {d, e }} \quad$ Ondrej Majek ${ }^{\text {d, e }}$ \\ Vera Adamkovaf, g \\ ${ }^{a}$ Experimental Medicine Centre, Institute for Clinical and Experimental Medicine, Prague, Czech Republic; \\ bThird Department of Internal Medicine, First Faculty of Medicine, Charles University, Prague, Czech Republic; \\ 'Department of Anthropology and Human Genetics, Faculty of Science, Charles University, Prague, Czech Republic; \\ dInstitute of Health Information and Statistics of the Czech Republic, Prague, Czech Republic; 'Institute of \\ Biostatistics and Analyses, Faculty of Medicine, Masaryk University, Brno, Czech Republic; f'Department of Preventive \\ Cardiology, Institute for Clinical and Experimental Medicine, Prague, Czech Republic; ${ }^{9}$ Department of Nephrology, \\ First Faculty of Medicine, Charles University, Prague, Czech Republic
}

\section{Dear Editor,}

We recently read with keen interest a study by Del Ser et al. [1], who suggest that carriers of APOE4 alleles come under increased risk of mild to moderate symptoms of coronavirus disease 2019 (COVID-19) during SARSCoV-2 infection. COVID-19 disease occurs as a consequence of infection with the RNA coronavirus SARSCoV-2. First reported in Wuhan, China, in December 2019, COVID-19 has since spread rapidly and has become a global pandemic [2]. Although highly contagious, the virus is nonetheless associated with relatively low mortality when compared with other coronavirus infections (MERS or SARS).

Apolipoprotein E (APOE, OMIM acc. ID - 107741, Gene ID - 348) is a small protein that plays an important role predominantly in lipid metabolism and cholesterol homeostasis. The 3 most common APOE alleles differ based on a single amino acid exchange as follows: APOE2 (Cys112, Cys158 - rs7412), APOE3 (Cys112 and Arg158), and APOE4 (Arg112 - rs429358, Arg158). APOE3 is the most common allele worldwide, exhibiting a population frequency of approximately $65-85 \%$. The ancestral allele $A P O E 4$, generally considered deleterious, is a significant

karger@karger.com

(c) 2021 S. Karger AG, Basel

www.karger.com/ger

Karger" risk factor for Alzheimer's disease and is also associated with atherosclerotic cardiovascular disease [3].

Using RT-PCR and the TaqMan assay (ID C_3084793_20), we analysed the APOE4 polymorphism (rs429358) in a group of 408 Czech first-wave (approximately March 2020-June 2020) SARS-CoV-2 PCR-positive (PCR test) subjects (54.7\% females, mean age $44 \pm 15$ years, diabetes prevalence $7.8 \%$, hypertension prevalence $13.3 \%)$. Of this total number, 164 were asymptomatic and 244 symptomatic [4]. All patients were confirmed SARSCoV-2-negative by the time of sample collection in July 2020. For comparison purposes, we consulted APOE4+ genotype (APOE4/E4, APOE4/E3, and APOE4/E2) frequencies in a large population-based cohort from the Czech part of post-MONICA study $(N=2,606 ; 53.6 \% \mathrm{fe}-$ males, mean age $48 \pm 11$ years, diabetes prevalence $8.2 \%$, hypertension prevalence 22.3\%) [5]. Information on COVID-19 status was not available for these subjects.

Detailed genotype frequencies are given in Table 1. We found no significant differences between the entire group of SARS-CoV-2-positive subjects and the control population ( $\chi^{2}$ test; $\left.p=0.11\right)$. However, after applying disease status (asymptomatic and symptomatic subjects were 
Table 1. Distribution of APOE4 allele carriers in controls and SARS-CoV-2-positive subjects

\begin{tabular}{|c|c|c|c|c|c|c|c|c|c|c|}
\hline \multirow[t]{2}{*}{ APOE } & \multicolumn{2}{|c|}{ Post-MONICA } & \multicolumn{2}{|c|}{$\begin{array}{l}\text { COVID-19 } \\
\text { asymptomatic }\end{array}$} & \multicolumn{2}{|c|}{$\begin{array}{l}\text { COVID-19 } \\
\text { symptomatic }\end{array}$} & \multirow{2}{*}{$\begin{array}{l}\text { OR }(95 \% \mathrm{CI}) \\
\text { controls versus } \\
\text { asymptomatic }\end{array}$} & \multirow[t]{2}{*}{$p$ value } & \multirow{2}{*}{$\begin{array}{l}\text { OR }(95 \% \mathrm{CI}) \\
\text { controls versus } \\
\text { symptomatic }\end{array}$} & \multirow[t]{2}{*}{$p$ value } \\
\hline & $N$ & $\%$ & $N$ & $\%$ & $N$ & $\%$ & & & & \\
\hline & 2,606 & & 164 & & 244 & & & & & \\
\hline $\mathrm{E} 4 / \mathrm{E} 4$ & 33 & 1.3 & 0 & 0 & 5 & 2.0 & N/A & N/A & $1.75(0.67-4.52)$ & 0.25 \\
\hline $\mathrm{E} 4 / \mathrm{EX}$ & 442 & 17.0 & 29 & 15.4 & 54 & 22.1 & $0.97(0.64-1.46)$ & 0.87 & $1.47(1.02-1.94)$ & 0.04 \\
\hline Other & 2,131 & 81.7 & 135 & 84.6 & 185 & 75.8 & 1.00 & & 1.00 & \\
\hline
\end{tabular}

EX, APOE3 or APOE2 allele; OR, odds ratio; CI, confidence interval; COVID-19, coronavirus disease 2019; APOE, apolipoprotein E. $p$ value calculated using the $\chi^{2}$ test. Values in bold indicate significance.

separately compared with the control population) to our model, the frequency of carriers of at least one APOE 4 allele was significantly higher in symptomatic COVID-19 subjects than in controls $(p=0.03$; OR, $95 \%$ CI -1.43 , $1.05-1.95)$. In contrast, genotype frequencies were almost identical in COVID-19-asymptomatic (SARS-CoV2-positive) subjects and in the control group population $(p=0.86)$.

Intriguingly, possible associations between the $A P O E$ polymorphism and COVID-19 have been mentioned before the study by Del Ser et al. [1] and our study have been performed. Theoretically, this idea was briefly elaborated by Goldstein et al. [6], based on the fact that the APOE4 allele is known to be more common in black Africans (population frequency: 30-40\%) than Caucasians (population frequency $\sim 7-20 \%$ ) and Asians (population frequency: 5-15\%) [7]. It has also been reported that the same ethnicity is affected by higher COVID-19 prevalence and mortality than other ethnic groups [8]. In fact, hundreds of SNPs have been shown to exhibit significant allelic differences (e.g., variants within the genes for apolipoprotein L1, alcohol dehydrogenase, and HFE) between ethnicities. Interestingly, however, none of these have been identified as potential predictors of COVID-19 severity using a GWAS approach. As such, ethnic differences per se are probably important for focusing, but insufficient at determining the genetic characteristics of COVID-19 candidate genes.

Importantly, based on a recent analysis of the UK Biobank Community Cohort, APOE polymorphism was found to have a considerable effect on COVID-19 severity [9]. The authors reported that carriers of APOE4E4 homozygotes were at increased risk of severe COVID-19, even after excluding individuals with diabetes, cardiovascular disease, and hypertension.
These findings underline the extreme pleiotropic complexity of the APOE gene (or possibly some adjacent clustering genes with variants in high linkage disequilibrium with the APOE4 allele). APOE is expressed in almost all human tissues, and its fundamental role in lipid transport is important for many functions, including immunity [10]. Further supporting the findings of the independent studies cited above, the results of our study indicate that the APOE4 allele is linked to increased risk of symptomatic COVID-19, making APOE the first gene to be associated with symptomatic COVID-19 disease directly in several independent studies.

\section{Statement of Ethics}

All subjects provided their written informed consent with the participation in the study. The study protocol (which is in agreement with Helsinki declaration of 1975) has been approved by the Multicentre Ethics Committee at the Institute of Biostatistics and Analyses, Faculty of Medicine, Masaryk University, Brno, Czech Republic (protocol ID - 01-110520/EK).

\section{Conflict of Interest Statement}

The authors have no conflicts of interest to declare.

\section{Funding Sources}

This study was supported by the Ministry of Health Czech Republic - Conceptual Development of Research Organisation (Institute for Clinical and Experimental Medicine - IKEM, IN 00023001). The sponsor played no role in the study design, data preparation or analysis, results interpretation, and manuscript preparation. 


\section{Author Contributions}

J.A.H. - funding, supervision, and writing major part of the manuscript. L.Dl. - data collection and genotype analysis. L.Du. - funding and supervision. O.M. - supervision, data collection, and interpretation. V.A. - funding, data interpretation, and supervision. All authors participated in designing the study protocol, interpreting the results, revising, and approving the final text.

\section{References}

1 Del Ser T, Fernández-Blázquez MA, Valentí M, Zea-Sevilla MA, Frades B, Alfayate E, et al. Residence, clinical features, and genetic risk factors associated with symptoms of COVID-19 in a cohort of older people in Madrid. Gerontology. 2021 Jan 11.

2 Liu YC, Kuo RL, Shih SR. COVID-19: the first documented coronavirus pandemic in history. Biomed J. 2020 Aug;43(4):328-33.

3 Mahley RW. Apolipoprotein E: from cardiovascular disease to neurodegenerative disorders. J Mol Med. 2016 Jul;94(7):739-46.

4 Hubacek JA, Dusek L, Majek O, Adamek V, Cervinkova T, Dlouha D, et al. CCR5Delta32 deletion as a protective factor in Czech firstwave COVID-19 subjects. Physiol Res. 2021 Mar 17;70(1):111-5.
5 Rynekrova J, Kasparova D, Adamkova V, Fait T, Hubacek JA. Analysis of the potential role of Apolipoprotein E polymorphism in genetic predisposition to spontaneous abortion. Am J Reprod Immunol. 2012 Mar;67(3):179-83.

6 Goldstein MR, Poland GA, Graeber ACW. Does apolipoprotein $\mathrm{E}$ genotype predict $\mathrm{CO}$ VID-19 severity? QJM. 2020 Aug 1;113(8): 529-30.

7 Abondio P, Sazzini M, Garagnani P, Boattini A, Monti D, Franceschi C, et al. The genetic variability of APOE in different human populations and its implications for longevity. Genes. 2019 Mar 15;10(3):222.
8 Lassale C, Gaye B, Hamer M, Gale CR, Batty GD. Ethnic disparities in hospitalisation for COVID-19 in England: the role of socioeconomic factors, mental health, and inflammatory and pro-inflammatory factors in a community-based cohort study. Brain Behav Immun. 2020 Aug;88:44-9.

9 Kuo CL, Pilling LC, Atkins JL, Masoli JAH, Delgado J, Kuchel GA, et al. APOE e4 genotype predicts severe COVID-19 in the UK Biobank community cohort. J Gerontol A Biol Sci Med Sci. 2020 Oct 15;75(11):2231-2.

10 Finch CE, Kulminski AM. The ApoE locus and COVID-19: are we going where we have been? J Gerontol A Biol Sci Med Sci. 2021 Jan 18;76(2):e1-3. 